ORIGINAL ARTICLE

\title{
The US gun stock: results from the 2004 national firearms survey
}

\author{
L Hepburn, M Miller, D Azrael, D Hemenway
}

Injury Prevention 2007;13:15-19. doi: 10.1136/ip.2006.013607

See end of article for authors' affiliations

.....................

Correspondence to:

Dr D Hemenway,

Department of Health Policy and Management, Harvard School of Public Health, 677 Huntington Avenue, Boston, Massachusetts, USA; hemenway@hsph.harvard. edu

Accepted 4 October 2006

\begin{abstract}
Objectives: To examine the size and composition of the privately held firearm stock in the US; and to describe demographic patterns of firearm ownership and motivations for ownership.

Design, setting and participants: A nationally representative household telephone survey of 2770 adults aged $\geqslant 18$ years living in the US, conducted in the spring of 2004.

Main outcome measure: Responses to questions regarding firearm ownership, the number and types of guns owned, and motivations for ownership.

Results: $38 \%$ of households and $26 \%$ of individuals reported owning at least one firearm. This corresponds to 42 million US households with firearms, and 57 million adult gun owners. $64 \%$ of gun owners or $16 \%$ of American adults reported owning at least one handgun. Long guns represent $60 \%$ of the privately held gun stock. Almost half (48\%) of all individual gun owners reported owning $\geqslant 4$ firearms. Men more often reported firearm ownership, with $45 \%$ stating that they personally owned at least one firearm, compared with $11 \%$ for women.

Conclusions: The US population continues to contain at least one firearm for every adult, and ownership is becoming increasingly concentrated. Long guns are the most prevalent type of gun in the US but handgun ownership is widespread. Ownership demographic patterns support findings of previous studies.
\end{abstract}

$\mathrm{T}$ he General Social Survey, a biannual survey of the US civilian population, has tracked household and personal firearm ownership over the past two and a half decades. ${ }^{1}$ This survey reports the percentage of households with firearms and personal firearm ownership for the nation as a whole and for the nine major census regions. Over the past 4 years, information from the General Social Survey has been supplemented by information on household gun ownership at the state level from the National Behavioral Risk Factor Surveillance System. ${ }^{2}$ A clear pattern that has emerged over the past several decades from these surveys is a persistent decline in household gun ownership. Although these surveys describe the demographic patterns of gun ownership in the US, they provide almost no information about the characteristics of or changes in the nation's gun stock.

We conducted a nationally representative household telephone survey in 2004 to explore the characteristics of privately owned firearms in the US. The last study to examine detailed questions like these, such as the types and numbers of working firearms in private homes, was conducted in 1994 by Cook and Ludwig. ${ }^{3}$ In their comprehensive report, they found that 35\% of households and $25 \%$ of individuals owned firearms, and estimated that there were 192 million working firearms in the US in private hands. In addition to describing demographic characteristics of firearm owners, they were able to determine that the ownership of private firearms was highly concentrated among a small percentage of owners. They also clearly identified a difference in the number of household firearms reported by married men and women, who, in theory, should report similar rates of household firearm ownership. Their findings, however, that married men reported a rate of $49 \%$ household firearm ownership compared with 36\% reported by married women suggested that women were either unaware of their spouse's firearm ownership or were reluctant to report it. These results led the authors to believe that more complete survey responses would come from individuals who personally owned a firearm rather than the household responses.
All of these findings helped identify patterns of private firearm ownership in the US and provided health professionals, researchers and policy makers with information about the private gun stock that was previously unknown. Through our survey, we wished to investigate possible changes in the privately owned gun stock between 1994 and 2004 and provide additional information about firearm ownership patterns in the US.

\section{METHODS}

The institutional review board at the Harvard School of Public Health approved this study in 2004. The random-digit-dial telephone sample (conducted by the survey research firm Fact Finders, St Louis, Missouri, USA) comprised 2770 randomly selected adults aged $\geqslant 18$ years living in the 50 states and including the District of Columbia. The number of interviews designated for each of the states was proportional to that state's population relative to the total population of the US as given by the 2000 census. The methods used in composing this sample assured that each household with a telephone had an equal probability of being selected for inclusion in the sampling frame. One adult from each household was randomly selected to participate.

Interviews were completed between 17 March and 28 June 2004. Once a telephone number had been randomly selected for inclusion in the survey sample, as many as 10 repeat phone calls were made until a final disposition was assigned. Of the 31302 telephone numbers called, 13117 (42\%) were nonresponses, $11065(35 \%)$ were not eligible and eligibility was unknown for 4338 (14\%). In total, $41 \%$ of the numbers were not residential, not in service or were for households in states where the interview quota had been reached. In addition, 39\% of interviews could not be completed because the maximum number of calls had been made without an eligible respondent answering the phone. Only 19\% (5421) of the non-interviews were refusals. According to calculations based on formulas from the American Association for Public Opinion Research, ${ }^{4}$ 
our minimum response rate was $14 \%$, assuming that all unknowns were eligible and counting partial interviews as respondents; and our maximum response rate was $18 \%$, assuming that all unknowns were ineligible.

Demographic characteristics including age, sex, education, marital status, race, presence of children in the home, whether the area was urban or rural, and household size of our sample were compared with those from the 2000 census. ${ }^{5}$ Although the demographic characteristics of our sample seemed similar overall to that of the census, our respondents had slightly higher educational levels (92\% $v$ total US $85 \%$ had at least a high-school diploma) and single-family households were fewer ( $19 \% v$ total US 26\%). Our sample also under-represented adult men aged 18-34 years. For that reason, post-stratification weightings were applied to the data to reflect the age and sex distribution of the US population. Adjustments for the likelihood of selection on the basis of the number of adults in the household were also included in the weightings.

Our study included 40 active duty military personnel, who represented $1.4 \%$ of the total study population. Eleven reported owning firearms; however, only one reported owning the firearm primarily for work. We therefore chose to keep all of the respondents in the sample.

Respondents were asked several questions regarding firearm ownership and use. In particular, they were asked, "Do you or anyone you live with currently have any guns in your home or motor vehicles? Not including toys, models, air guns or starter pistols." If the response was affirmative, the respondent was then asked, "In total, how many guns do you and anyone you live with currently have in your home or motor vehicle?" All respondents who replied that there were guns in their household were asked how many of each type of firearm was in their home (ie, revolvers, shotguns) and if they were in working order. To determine the proportion of adults who personally owned firearms, we asked those respondents who had replied that there were guns in their home, "Do any guns in your home belong to you personally?"

\section{Statistical analyses}

Descriptive and bivariate analyses were used to explore the relationships between firearm ownership, demographics, concentration and motivations for ownership. As previously mentioned, research suggests that individuals who personally own firearms report firearm ownership more accurately than non-owners who live in households with firearms. ${ }^{6-8}$ All of our reported analyses are therefore based on responses from individual gun owners rather than respondents living in households with guns, unless specifically noted that the calculation was performed using household responses.

To produce national estimates of the number of firearms in the US, we used population figures from the US census ${ }^{9}$ to determine the number of adults aged $\geqslant 18$ years and the number of households in the US. We then calculated the percentage of respondents in our survey who reported personally owning a firearm. This number was applied to the US population to create national estimates of the number of adults who owned firearms. To estimate the number of firearms in private hands, we multiplied the number of firearm owners by the average number of firearms reported by respondents in our survey. As firearm ownership is not normally distributed and our survey included some extreme outliers in terms of the number of firearms owned, we performed calculations excluding the outliers. As a sensitivity analysis, similar calculations were performed using household reports of firearm ownership. We also conducted comparative analyses among men and women, and among respondents who lived alone and those living in multi-person households.

\section{RESULTS}

Firearm owners reported that $60 \%$ of the firearms owned in the US in 2004 were long guns, primarily rifles and shotguns (fig 1); the remaining $40 \%$ were handguns. Among all firearms, rifles were the most common, representing $33 \%$ of the gun stock. Revolvers were the most common type of handgun. A small percentage of respondents (5\%) reported owning other handguns, including derringers and antique handguns. Other long guns, which include muzzle loaders and antique long guns, represented $6 \%$.

According to our survey, $38 \%$ of households reported at least one firearm in the home and $26 \%$ of adults reported owning at least one gun. This corresponds to 42 million households with firearms and 57 million adult gun owners. We found that $64 \%$ of gun owners or $16 \%$ of adults reported owning at least one handgun; $80 \%$ of gun owners or $20 \%$ of all adults owned a long gun (results not shown).

\section{Ownership demographics}

Firearm ownership was more prevalent among middle-aged and older adults than among young adults aged 18-24 years (table 1). Ownership of any firearm was more common among men, those who were married or living with a partner, and respondents living in rural areas or the South. Ownership was strongly associated with whether the respondent grew up with guns in the home. Among gun-owning households in our survey, $46 \%$ had $\geqslant 1$ adult gun owner.

\section{Reasons for ownership}

When respondents were asked, "What is the one most important reason that you own a handgun/long gun?" the most common response among those who owned a handgun was for self-defense (46\%), followed by sport shooting (hunting or target shooting) or collecting (25\%). Owners of long guns overwhelmingly reported sport shooting as the "most important" reason to own a long gun (77\%; data not shown).

\section{Concentration of ownership}

Almost half (48\%) of all individual gun owners, corresponding to $13 \%$ of the US adult population, reported owning $\geqslant 4$ firearms. Household ownership followed a similar pattern, with $41 \%$ of firearm-owning households reporting ownership of $\geqslant 4$ firearms (table 2). The $20 \%$ of gun owners who owned the most guns possessed about $65 \%$ of the nation's guns.

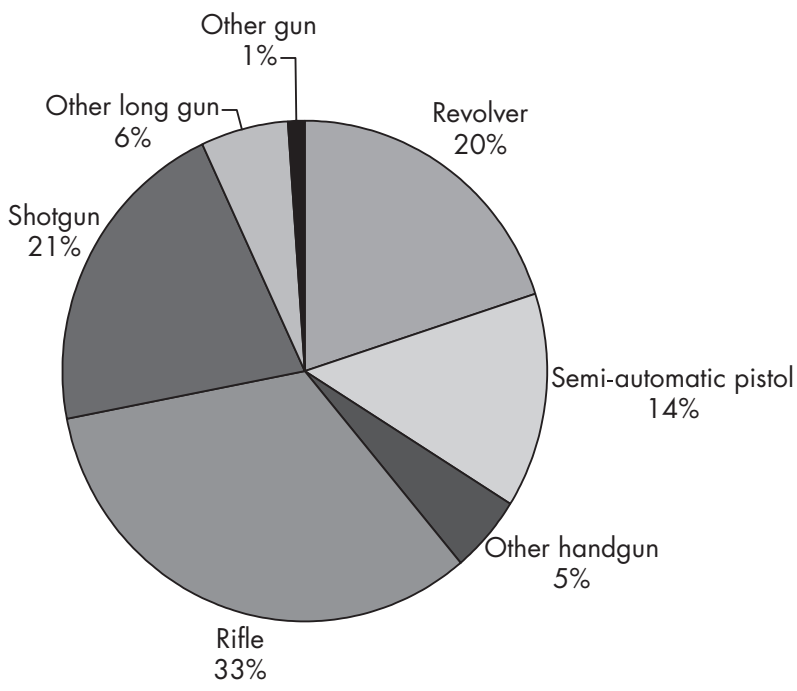

Figure 1 Types of firearms owned in the US. 
Table 1 Demographic characteristics of firearm owners

\begin{tabular}{|c|c|c|c|c|c|}
\hline & $\mathbf{n}$ & $\begin{array}{l}\text { Owns any } \\
\text { firearm, } \\
n=726 \\
(\%)\end{array}$ & $\begin{array}{l}\text { Owns both } \\
\text { handguns } \\
\text { and long guns, } \\
n=322 \\
\text { (\%) }\end{array}$ & $\begin{array}{l}\text { Owns handguns } \\
\text { only, } \\
n=127 \\
\text { (\%) }\end{array}$ & $\begin{array}{l}\text { Owns long } \\
\text { guns only, } \\
n=215 \\
(\%)\end{array}$ \\
\hline Total & 2770 & 26 & 12 & 5 & 8 \\
\hline \multicolumn{6}{|l|}{ Age (years) } \\
\hline$<25$ & 216 & 16 & 6 & 3 & 7 \\
\hline $25-44$ & 903 & 26 & 11 & 5 & 8 \\
\hline $45-64$ & 1058 & 30 & 15 & 5 & 8 \\
\hline$\geqslant 65$ & 545 & 27 & 12 & 5 & 7 \\
\hline \multicolumn{6}{|l|}{ Sex } \\
\hline Male & 1363 & 42 & 20 & 5 & 13 \\
\hline Female & 1407 & 11 & 3 & 4 & 3 \\
\hline \multicolumn{6}{|l|}{ Race } \\
\hline White & 2178 & 30 & 14 & 4 & 9 \\
\hline Non-white & 592 & 15 & 5 & 5 & 3 \\
\hline \multicolumn{6}{|l|}{ Marital status } \\
\hline Single & 953 & 18 & 7 & 4 & 6 \\
\hline Married or living with partner & 1786 & 30 & 14 & 5 & 8 \\
\hline \multicolumn{6}{|l|}{ Community } \\
\hline Urban & 687 & 18 & 8 & 5 & 5 \\
\hline Suburban & 1161 & 23 & 10 & 5 & 7 \\
\hline Rural & 872 & 37 & 18 & 4 & 11 \\
\hline \multicolumn{6}{|l|}{ Education } \\
\hline High school or less & 920 & 26 & 10 & 3 & 10 \\
\hline Some college/associated degree & 930 & 29 & 12 & 6 & 8 \\
\hline Bachelors or higher & 904 & 23 & 12 & 4 & 5 \\
\hline \multicolumn{6}{|l|}{ Annual income } \\
\hline$<\mathrm{US} \$ 40000$ & 1120 & 21 & 8 & 4 & 8 \\
\hline$>$ US $\$ 40000$ & 1282 & 30 & 15 & 6 & 8 \\
\hline \multicolumn{6}{|l|}{ Military service } \\
\hline Veteran & 404 & 53 & 27 & 8 & 12 \\
\hline Current military & 40 & 31 & 14 & 4 & 8 \\
\hline No & 2316 & 22 & 9 & 4 & 7 \\
\hline \multicolumn{6}{|l|}{ Political views } \\
\hline Liberal & 594 & 16 & 7 & 4 & 4 \\
\hline Moderate & 861 & 26 & 11 & 5 & 9 \\
\hline Conservative & 1019 & 32 & 16 & 6 & 8 \\
\hline \multicolumn{6}{|l|}{ Region } \\
\hline Northeast & 530 & 17 & 7 & 2 & 7 \\
\hline Midwest & 635 & 27 & 12 & 3 & 10 \\
\hline South & 986 & 32 & 14 & 7 & 8 \\
\hline West & 619 & 24 & 10 & 5 & 6 \\
\hline \multicolumn{6}{|l|}{ Child aged $<18$ years } \\
\hline Yes & 1016 & 27 & 12 & 4 & 9 \\
\hline No & 1749 & 26 & 12 & 5 & 7 \\
\hline \multicolumn{6}{|l|}{ Parents had a gun at home } \\
\hline Yes & 1647 & 40 & 18 & 6 & 12 \\
\hline No & 1103 & 7 & 3 & 2 & 2 \\
\hline
\end{tabular}

\section{Number of guns}

The actual number of guns reported in our survey varied depending on how the question was asked and who answered the question. Individual firearm owners $(n=702)$ reported owning an average of 6.6 (95\% confidence interval (CI) 5.2 to 7.9, median 3) working firearms. On further examination, it seemed that individuals who owned $\geqslant 4$ firearms (with an average of 12 firearms per person) were greatly affecting the mean. When outliers representing the top 3\% of gun owners (those owning $>25$ guns) were removed, the average number of working firearms per owner was 5.0 (95\% CI 4.6 to 5.4 ). On the basis of estimates of $26 \%$ of adults in the US owning at least one firearm, we estimated that 57 million adults owned 283 million firearms (95\% CI 260 to 305 million).

Estimates based on the number of household firearms were lower. We estimated that 42 million households in the US possessed at least one firearm in 2004, with an average of 5.2 (95\% CI 4.9 to 5.6) guns per household, with outliers of $>25$ guns removed. The number of privately owned firearms in the US based on these estimates would be 218 million (95\% CI 206 to 235 million).

\section{Reporting differences}

Overall, men and women reported different rates of household firearm ownership. Among married respondents who lived in two-adult households, married men reported a household firearm ownership rate of $54 \%$ and an average of 8 firearms per household compared with a $40 \%$ ownership rate and an average of 4.6 guns as reported by married women (table 3 ).

\section{DISCUSSION}

In general, our survey results are consistent with previous reports of firearm ownership demographics. ${ }^{1}{ }^{10}$ Firearms are most likely to be owned by white men who live in a rural areas, those who are middle-aged or older, with a middle to higher income, who grew up with guns in the home and who live in the southern or mid-western regions of the country. Long guns continue to be the most prevalent type of gun in the US. Our survey, however, reports a slightly higher percentage of firearms that are handguns than that reported in $1994^{3}(40 \%$ $v 34 \%$ ). This shift to a greater proportion of handguns may be reflective of the decline in hunting and indicate a change in motivations and use of firearm ownership. ${ }^{10}$ Similar to previous 
Table 2 Distribution of firearm ownership in the US population

\begin{tabular}{lcc}
\hline & \multicolumn{2}{c}{ Percentage of US population } \\
\cline { 2 - 3 } Firearms owned & Individuals* & Households* \\
\hline 1 & 6 & 8 \\
2 & 4 & 6 \\
3 & 3 & 4 \\
$\geqslant 4$ & 13 & 16 \\
Any firearm & $26 \dagger$ & $39 \dagger$ \\
\hline
\end{tabular}

${ }^{*}$ Calculations based on the number of individuals who reported an actual number of firearms; $5 \%$ of households that reported owning a firearm did not report the number of firearms present in their home.

†These numbers are calculated using the affirmative response to owning a firearm.

surveys, ${ }^{3}{ }^{10}$ handgun owners were most likely to report owning their handguns for self-protection, whereas owners of long guns reported owning their guns for sporting purposes. Individuals who own only handguns are just as likely to live in an urban environment as a rural one and are demographically more diverse compared with owners of only long guns who are more likely to be men and live in a rural area.

Our findings diverge from those of previous studies on firearm ownership regarding the increase in the average number of guns per gun owner. Although the rate of individual $(26 \%)$ and household (38\%) ownership is similar to that in other recent surveys, ${ }^{1-3}{ }^{11}$ the number of guns reported per person is higher. When including outliers, gun owners reported an average of 6.9 guns per owner compared with 4.1 reported in 1994 (J Ludwig, personal communication, 12 January 2005). The higher average number of guns in our survey is attributable to the higher number of guns owned by those who owned $\geqslant 4$ guns, as the percentage of gun owners in each category of gun ownership (those owning $1-3$ or $\geqslant 4$ guns) has stayed almost the same.

Cook and Ludwig ${ }^{3}$ reported an estimate of 192 million working firearms in circulation in 1994. Although the population increased $11 \%$ between 1994 and 2004, population growth alone does not explain the differences in the number of guns reported. A recent report by the National Research Council, using national data on firearms manufactured, imported and exported, estimated that 258 million firearms were available in the US as of 1999. ${ }^{12}$ This estimate does not account for firearm loss, breakage or those destroyed. When we calculated the number of guns in the same manner as in the National Research Council report, adding all available years, we calculated that about 275 million guns were manufactured or imported for private sale in the US by the end of 2003. As the US does not require firearms to be registered (although some individual states do), it is impossible to determine the exact number of privately owned firearms in this country.

Our estimates of 283 million firearms in the US may be higher than those that Cook and Ludwig established in 1994, even with the population growth kept in context, for many possible reasons. Our sample may have, by chance, captured more affluent firearm owners who own many guns. We adjusted for age and sex, but were unable to adjust for income because our income-related questions were not comparable with a standard such as the US census. Alternatively, respondents may have overestimated the number of guns they owned. Given that we are extrapolating from a survey of 2770 respondents to millions of Americans, small changes in the number of reported firearms results in a large difference in the national estimates.
Table 3 Rates of household firearm ownership, median and average number of guns per household for men and women

\begin{tabular}{llll}
\hline & $\begin{array}{l}\text { Ownership } \\
\text { rate }\end{array}$ & $\begin{array}{l}\text { Average number } \\
\text { of guns }\end{array}$ & Median \\
\hline Men & 49 & 7.9 & 5 \\
Women & 30 & 4.1 & 3 \\
Married men & 54 & 8.0 & 4 \\
Married women & 40 & 4.6 & 3 \\
Men who live alone & 39 & 6.8 & 3 \\
Women who live alone 12 & 2.5 & 2 \\
\hline
\end{tabular}

The General Social Survey indicates that household gun ownership has been declining over time, from about 50\% in the early 1970s to current estimates of $34 \%{ }^{1}$ Although the exact number of firearms in the US may be debatable as a result of inclusion or exclusion of outliers, or whether individual or household responses are used, it seems that although the proportion of households with firearms is declining, the number of working firearms in the US is increasing, not decreasing, and increasing most among those who already own firearms.

We also found evidence to support earlier research showing that women report lower levels of household firearm ownership, and in particular report fewer guns per household than men. ${ }^{6-8}$ Married women in our study reported an average of 3.4 fewer household guns than married men and a difference in ownership of $14 \%$ ( $54 \%$ in men $v 40 \%$ in women). These findings reinforce earlier recommendations for surveys of firearm ownership and behavior, ${ }^{6}$ to seek information from individual firearm owners rather than any person living in a household with a firearm.

\section{Limitations}

We have considered some of the challenges faced when conducting telephone surveys, in particular those related to asking household members to respond to questions about topics, in this case firearm ownership, which may pertain to other members of the household. This self-reported data may also be subject to potential inaccuracies due to recall bias or the tendency to report socially desirably responses. ${ }^{13}$ For example, when we asked respondents two different questions to determine how many firearms were in their households, one asking for the total number of guns in the home and one asking specifically how many of each type of gun were owned, we often received two different numbers. Given that this was a telephone survey, we were limited to adults with access to a working telephone. If households without telephones were more or less likely to own a firearm, then our findings could be biased in the respective directions. Finally, non-response can

\section{Key points}

- Firearm ownership in the US is very common, with about one third of all households owning at least one firearm.

- Long guns are the most prevalent type of gun in the US, but $40 \%$ of the gun stock is handguns.

- Firearm ownership is highly concentrated, with a small number of adults owning a large proportion of the nation's firearms.

- Married men and women report different rates of household firearm ownership, supporting the proposal that researchers should seek information about firearm ownership from individual firearm owners. 
affect the validity of our findings if those choosing not to answer a question differed systematically from those who did. ${ }^{14}$ The low response rate in this survey is similar to other randomdigit-dial telephone surveys ${ }^{15}$; however, it still allows for potential bias if those who participated in the survey differed in terms of firearm ownership from those who did not.

\section{CONCLUSIONS}

\section{Implications for prevention}

In the US, about one in four adults owns at least one firearm. Although some other developed countries have similar rates of personal firearm ownership, what is unique in the US is the number of firearms privately owned. Researchers have estimated about 25 guns per 100 people in countries such as Canada, New Zealand, Germany, France and Sweden. ${ }^{16}$ On the basis of current estimates from our survey, the US has 93 guns per 100 people.

The National Academy of Sciences recently issued a report on firearms and violence in which they called for improved data on firearm ownership and use to advance the empirical evaluations of programs and policies to reduce gun violence. ${ }^{12}$ Our findings describe the current motivations for firearm ownership and also provide information on the similarities and differences among owners of different types of guns. This information can assist in designing a more appropriate firearm injury policy as well as understanding the denominator of exposure when evaluating injury prevention interventions.

\section{ACKNOWLEDGEMENTS}

We thank Renee Johnson for her help in determining the response rate for this survey.

\section{Authors' affiliations}

L Hepburn, M Miller, D Azrael, D Hemenway, Department of Health Policy and Management, Harvard School of Public Health, Boston,

Massachusetts, USA
Funding: This research was supported in part by grants from the Joyce Foundation, the Robert Wood Johnson Foundation and the Soros Foundation.

Competing interests: None.

\section{REFERENCES}

1 National Opinion Research Center. General Social Survey. 2004. http:// www.norc.uchicago.edu/projects/gensoc.asp (accessed 2 Nov 2006).

2 Centers for Disease Control and Prevention. Behavioral Risk Factor Surveillance System Survey Data. Atlanta: CDC, 2002.

3 Cook PJ, Ludwig J. Guns in America: results of a comprehensive national survey on firearms ownership and use. Washington, DC: Police Foundation, 1997

4 American Association for Public Opinion Research. Standard definitions: final dispositions of case codes and outcome rates for surveys. Ann Arbor, MI: American Association for Public Opinion Research, 2000.

5 US Bureau of the Census. Statistical abstract of the United States. http:// www.census.gov/compendia/statab (accessed 2 Nov 2006).

6 Ludwig J, Cook PJ, Smith TW. The gender gap in reporting household gun ownership. Am J Public Health 1998;89:1715-18.

7 Azrael D, Miller M, Hemenway D. Are household firearms stored safely? It depends on whom you ask. Pediatrics 2000;106:31.

8 Coyne-Beasley T, Baccaglini L, Johnson R, et al. Do partners with children know about firearms in their home? Evidence of a gender gap and implications for practitioners. Pediatrics 2005; 115:e662-7.

9 Bureau of Labor Statistics. Current population survey. Washington, DC: Bureau of Labor Statistics, 2004.

10 Smith TW. 2001 National Gun Policy Survey of the National Opinion Research Center: research findings. Chicago: National Opinion Research Center, University of Chicago, 2001.

11 Okoro C, Nelson DE, Mercy JA, et al. Prevalence of household firearms and firearm-storage practices in the 50 states and the District of Columbia: findings from the Behavioral Risk Factor Surveillance System, 2002. Pediatrics 2005;116:370-6

12 National Research Council. Firearms and violence: a critical review. Washington, DC: National Academics Press, 2004.

13 Aday L. Designing and conducting health surveys. San Francisco: Jossey-Bass, 1989.

14 Frey J. Survey research by telephone, 2nd edn. Newbury Park, CA: Sage, 1989.

15 Johnson T, Owens L. Survey response rate reporting in the professional literature. American Association for Public Opinion Research-Section on Survey Research Methods, Chicago, Illinois: 2004:127-33.

16 Graduate Institutes of International Studies. Small Arms Survey: profiling the problem. Geneva: Oxford University Press, 2001. 